\title{
Ectopic Pregnancy in Cesarean Scar. Case Report
}

\author{
Guallan Federico ${ }^{1}$, Camargo Alfredo ${ }^{2}$ and Illia Ricardo ${ }^{3 *}$ \\ ${ }^{1}$ Chief Residents of Gynecology Service, Hospital Alemán, Argentina \\ ${ }^{2}$ Chief of Breast Pathology, Sanatorio Guemes, Argentina \\ ${ }^{3}$ Department of Obstetrics, Buenos Aires University, Argentina
}

*Corresponding author: Ricardo Illia, Department of Obstetrics, Buenos Aires University, Fellow ACOG Buenos Aires Argentine Section, Chief of Obstetrics Service, Hospital Alemán, Buenos Aires, Argentina.

Received Date: July 24, 2018

Published Date: August 20, 2018

\section{Introduction}

Ectopic pregnancy on the scar of a previous cesarean is a very rare entity with a prevalence ranging from 1 : 1,800 to 1 : 2,226 pregnancies [1] and corresponds to only $6 \%$ of ectopic pregnancies in women with a previous cesarean section [2]. Its increasing incidence in recent years is associated not only with the increase in the number of caesarean sections, but also with the increase of scarring in the endometrium due to uterine curettage, myomectomies, hysteroscopies, manual delivery of the placenta and assisted fertilization techniques [3]. We present a case report of a patient with a serious complication due to this pathology.

\section{Case Report}

A37-year-old patient, G2P1 (s-section), with a 7-week pregnancy with a diagnosis of missed miscarriage, evidencing a gestational sac descended in the Transvaginal Ultrasound. A uterine evacuation was performed on $4 / 26 / 18$, evolving with a profuse intraoperative uterine bleeding, which required uterine artery embolization and ICU admission (15\% Ht on admission) with transfusion of 5 units of red blood cells. She progressed with hemodynamic stability, without uterine bleeding for the next 96 hours, with control hematocrit at discharge of $31 \%$. She developed fever 7 days after discharge (11th postoperative day) so she is readmitted. A CT-scan of the abdomen and pelvis is performed. It showed a prevesical hipoechogenic mass with peripheral reinforcement of $8 \mathrm{~cm} \mathrm{x} 6 \mathrm{~cm}$ compatible with abscess vs. hematoma.

Given the suspicious of a hematoma in the uterine segment versus complicated Ectopic Pregnancy of a cesarean scar, a laparotomic approach was decided, finding an $8 \mathrm{~cm}$ mass, with a hematoma aspect, contained by uterine serosa, which compromises the entire uterine segment, and with tight adherence to the dome of the bladder. Given the impossibility of performing a conservative treatment due to the size and total compromise of the uterine segment, we decided to perform a total hysterectomy (Figure 1-3).

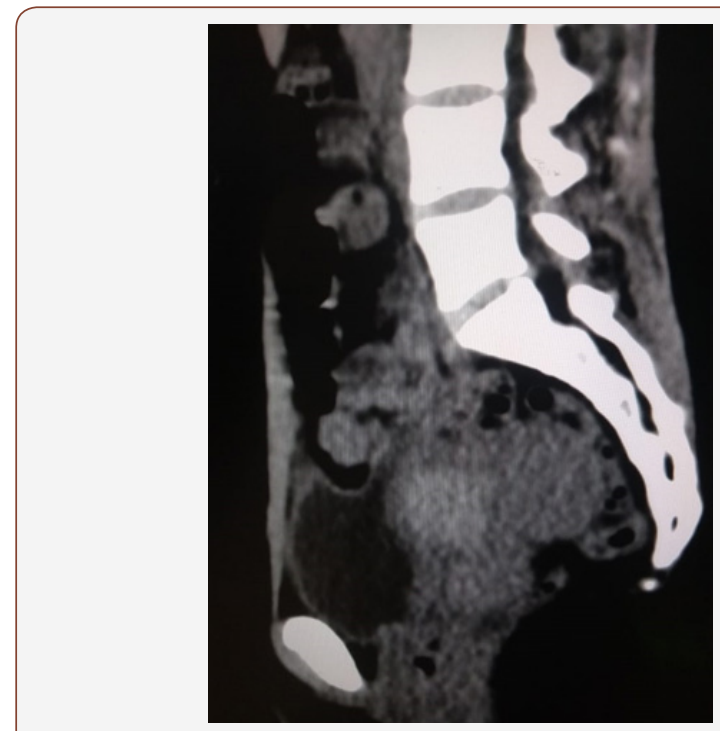

Figure 1: CT scan showing a prevesical hipoechogenic mass of about $8 \mathrm{~cm}$ of diameter.

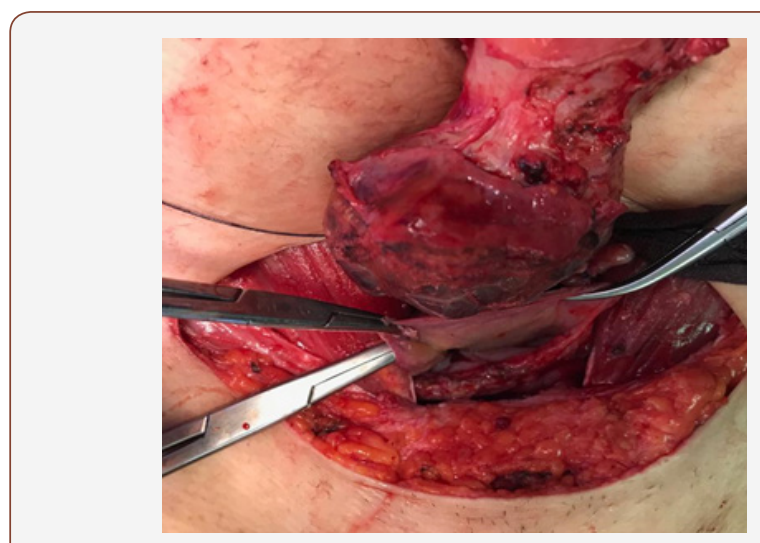

Figure 2: Uterine segment mass, firmly adherent to the dome of the bladder, which was opened. 


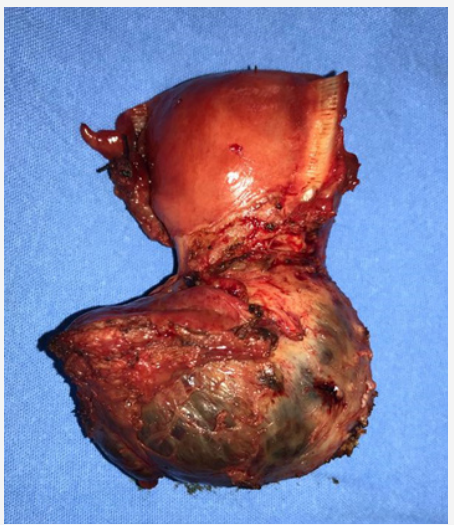

Figure 3: Total hysterectomy anatomopathology piece, showing a big and vascularized hematoma in the uterine segment.

\section{Discussion}

Transvaginal ultrasound with color doppler is the gold standard for diagnostic, with a high sensitivity and specificity, with a low rate of false positives. The most common sonographic signs are: 1) emptiness of endometrial fundus, 2) descending gestational sac, located in the anterior part of the isthmus, with myometrium thinned in the underlying area, 3) discontinuation of the anterior uterine wall in a sagittal section 4) increase of peritofoblastic vascularization around the trophoblastic mass [4]. Ultrasound assessment of the relationship between the gestational sac of a CSP and the endometrial line (the COS) may help to determine whether a cesarean scar pregnancy will progress towards a less severe form of morbidity adherential process, amenable to postnatal treatment, and successful pregnancy outcome [5]. The differential diagnosis should be made with cervico-isthmic implantation of pregnancy, cervical ectopic pregnancy and spontaneous miscarriage in progress [6].

Early diagnosis and treatment can prevent uterine rupture, severe hemoperitoneum, and hysterectomy, decreasing severe maternal morbidity [7].

In cases in which the diagnosis was made early, and the patient shows hemodynamic stability, measurement of the anterior uterine wall is essential, since when it is less than $2 \mathrm{~mm}$, and the trophoblast reaches the vesicouterine space above the bladder wall, a non-surgical procedure is more appropriate rather than extensive surgery [8]. Medical treatment consists in the administration of Methotrexate (MTX) systemically or locally [9]. Fine-needle aspiration of fluid remaining in the gestational sac may also be necessary [10]. Other authors use the combination of intracardiac potassium chloride in the embryo and intrasaccular MTX [11].
The surgical approach can be performed hysteroscopically [11], laparoscopically or laparotomically by wedge resection of the previous scar with new hysterorrhaphy, in cases where fertility is desired, or total hysterectomy in cases where it is not desired to conserve fertility.

\section{Conclusion}

Suspicious and early diagnosis of ectopic pregnancy of cesarean section can conserve fertility and can reduce maternal morbidity and mortality. There is no single treatment modality, and none can guarantee uterine integrity. The treatment must be adapted to each patient and take into account the consideration of the viability of pregnancy, gestational age, and future family planning. Expectant management is not an option given the high risk of uterine rupture and hemoperitoneum.

\section{References}

1. Seow KM, Huang LW, Lin YH, Lin MY, Tsai YL (2004) et al. Cesarean scar pregnancy: issues in management. Ultrasound Obstet Gynecol, 23(3): 247-253.

2. Ndubizu C, Mc Laren Jr RA, McCalla S, Irani M (2017) Recurrent cesarean scar ectopic pregnancy treated with systemic methotrexate. Case Reports in Obstet Gynecol 2017: 1-4.

3. Ash A, Smith A, Maxwell D (2007) Cesarean scar pregnancy. BJOG 114(3): 253-263.

4. Maymon R, Halperin R, Mendlovic S, Schneider D, Herman A (2004) Ectopic pregnancies in a caesarean scar: review of the medical approach to an iatrogenic complication. Hum Reprod Update 10(6): 515-523.

5. Cali G, Forlani F, Timor-Tritsch IE, Palacios-Jaraquemada J, Minneci G, et al. (2017) Natural history of cesarean scar pregnancy on prenatal ultrasound: the crossover sign. Ultrasound Obstet Gynecol 50(1): 100104.

6. Tsai SW, Huang KH, Ou YC, Hsu TY, Wang CB, et al. (2013) Low-lyingimplantation ectopic pregnancy: a cluster of cesarean scar, cervicoisthmus, and cervical ectopic pregnancies in the first trimester. Taiwan J Obstet Gynecol 52(4): 505-511.

7. Egbe TO, Halle-Ekane GE, Tchente CN, Nyemb JE, Belley-Priso E (2016) Management of uterine rupture: a case report and review of the literature. BMC Res Notes (9): 492

8. Ghezzi F, Laganà D, Franchi M, Fugazzola C, Bolis P (2002) Conservative treatment by chemotherapy and uterine arteries embolization of a cesarean scar pregnancy. Eur J Obstet Gynecol Reprod Biol 103(1): 8891.

9. Litwicka K, Greco E (2011) Caesarean scar pregnancy: a review of management options. Curr Opin Obstet Gynecol 23(6): 415-421.

10. Koothan V, Bharatwaj RS, Himabindhu N, Bhattacharyya LM (2012) Trans-cervical fine needle aspiration of the amniotic fluid in a cervical pregnancy: taming the hornet's nest. J Clin Diagn Res 6: 1304-1305.

11. Deka D, Bahadur A, Singh A, Malhotra N (2012) Successful management of heterotopic pregnancy after fetal reduction using potassium chloride and methotrexate. J Hum Reprod Sci 5(1): 57-60.

12. Deans R, Abbott J (2010) Hysteroscopic management of cesarean scar ectopic pregnancy. Fertil Steril 93(6): 1735-1740. 